\title{
Mineral equilibrium in commercial curd and predictive ability of near-infrared spectroscopy
}

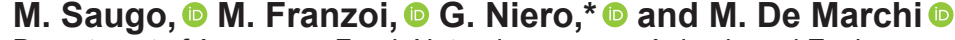 \\ Department of Agronomy, Food, Natural resources, Animals and Environment, University of Padova, Viale dell'Università 16, \\ 35020 Legnaro (PD), Italy
}

\begin{abstract}
Curd samples $(\mathrm{n}=83)$ from 3 European dairy companies were analyzed for micellar and soluble mineral fractions content using inductively coupled plasma optical emission spectrometry as a gold standard method. The same curd samples were analyzed through 3 different near-infrared (NIR) instruments, and NIR spectra were merged with reference data. Prediction equations were developed using modified partial least squares analysis, and the accuracy of prediction was evaluated through leave-one-out cross validation. Overall, NIR spectroscopy was capable of predicting micellar and soluble mineral fractions in curd, but with differences among instruments. Fitting statistics showed that the visible NIR instrument in reflectance mode outperformed the NIR instrument in transmittance mode as well as the portable NIR instrument in reflectance mode. Prediction accuracies for most of the analyzed mineral fractions can be used for curd quality control in dairy companies and to aid in decision-making during the cheesemaking process.
\end{abstract}

Key words: element, micellar fraction, soluble fraction, dairy

\section{INTRODUCTION}

Curd is a product of enzymatic coagulation or acidic precipitation of milk constituents. Cheese curd represents an important intermediate product in cheese manufacturing, allowing easier conservation and transport compared with raw milk. Mineral equilibrium in milk plays an important role in curd manufactured through enzymatic coagulation because $\mathrm{Ca}$ and $\mathrm{P}$ are directly involved in curd formation through the stabilization of casein micelles (Holt, 2016). Together with milk Mg, milk $\mathrm{Ca}$ is also involved in paracasein reticulum formation, acting as a bridge between casein micelles (Lucey

Received April 14, 2020

Accepted October 26, 2020.

*Corresponding author: giovanni.niero@phd.unipd.it and Fox, 1993; Malacarne et al., 2014). On the other hand, mineral equilibrium in curd can have an effect on the determination of curd quality, the assessment of technological traits used for curd formation, and the understanding of the behavior of the curd (and minerals) in the following processing steps.

Although total mineral quantification in dairy products is a common procedure involving an acidic digestion step followed by direct quantification through different induced couple plasma protocols, the distinction between micellar and soluble mineral fractions is not negligible (Lante et al., 2006; Reykdal et al., 2011). Recently, Franzoi et al. (2018) proposed a new method for the quantification of the 2 mineral fractions in milk based on a double step dilution of enzymatically coagulated samples. The method allows for the direct quantification of micellar and soluble fractions without the need of correction factors that could introduce a bias in estimated mineral amounts. Nevertheless, the method is still demanding in terms of trained personnel, costs, and time.

Near-infrared (NIR) spectroscopy has been recognized as a methodology to overcome such problems because it is fast and cost-effective for the characterization of routine samples; it is already used in many dairy companies for the routine characterization of samples and as an internal check of final products (De Marchi et al., 2014). To our knowledge, there is limited information about curd mineral quantification using NIR spectroscopy, in particular as it regards mineral fractions. The aims of the present study were to (1) quantify soluble and micellar mineral fractions of commercial curds, (2) assess the relationships between mineral fraction content and chemical composition, and (3) investigate the ability of NIR spectroscopy to predict the content of soluble and micellar fractions.

\section{MATERIALS AND METHODS}

\section{Sample Collection}

Eighty-three commercial curd samples intended for mozzarella cheese production were collected between 
January and May of 2019 from 3 European dairy companies. Thirty-five samples were imported frozen from European countries, and 48 samples were produced in Italy (16 using imported milk from European countries and 32 using Italian milk). The latter samples were immediately frozen and stored at $-20^{\circ} \mathrm{C}$ until chemical analysis. Analyses were conducted in the laboratory of the Department of Agronomy, Food, Natural resources, Animals and Environment (DAFNAE, Legnaro, PD, Italy) of the University of Padova (Padova, Italy).

Samples were thawed at $4^{\circ} \mathrm{C}$ for $48 \mathrm{~h}$, homogenized with a knife mill (Grindmix GM200; Retsch GmbH, Haan, Germany), and analyzed for total protein, soluble protein, humidity, fat, and ash content using FoodScan Lab calibrated with Foss Artificial Neutral Networks Dairy Calibration (Foss, Electric A/S, Hillerød, Denmark). Successively, curd samples were divided in 2 aliquots: the first aliquot intended for mineral content analysis and the second aliquot intended for NIR spectra collection.

\section{Mineral Analysis}

Ultrapure water was produced with Arium 611 UV (Sartorius, Monza Brianza, Italy), and all chemicals, if the supplier is not mentioned, were purchased from Sigma-Aldrich (St. Louis, MO) at the highest available purity. Total, micellar, and soluble minerals were analyzed following the method proposed by Franzoi et al. (2018) with necessary modifications. After homogenization, 10 $\mathrm{g}$ of curd was immediately frozen for quantification of total minerals, and $20 \mathrm{~g}$ was introduced in a tube with $10 \mathrm{~mL}$ of ultrapure water. The tube was incubated for $2 \mathrm{~h}$ at $37^{\circ} \mathrm{C}$ in a water bath. Samples were centrifuged at $5,000 \times g$ for $20 \mathrm{~min}$ at $25^{\circ} \mathrm{C}$, and $5 \mathrm{~mL}$ of the supernatant was collected and filtered with a $0.45-\mu \mathrm{m}$ membrane $\left(\mathbf{d}_{1}\right)$. Then, $5 \mathrm{~mL}$ of ultrapure water was added to the tube, vortexed for $20 \mathrm{~s}$, and left for $1 \mathrm{~h}$ at $37^{\circ} \mathrm{C}$ in a water bath to equilibrate the soluble phase. Samples were centrifuged as described previously, and $5 \mathrm{~mL}$ of supernatant was collected and filtered with a $0.45-\mu \mathrm{m}$ membrane $\left(\mathbf{d}_{\mathbf{2}}\right)$. To determine how and to what extent the use of ultrapure water could affect the $\mathrm{pH}$, we determined the $\mathrm{pH}$ of the soluble phases before and after dilution. Differences in $\mathrm{pH}$ for tested samples were always between 0.0 and +0.2 (data not shown). All obtained fractions were stored frozen until the quantification procedure, which was performed using inductively coupled plasma optical emission spectrometry (ICP-OES) as described by Visentin et al. (2016) and Franzoi et al. (2018). Briefly, samples were digested by nitric acid in a microwave Milestone Start D apparatus (Milestone Srl, Sorisole, Italy) and analyzed through ICP-OES Spectro Arcos (Spectro Analytical Instruments GmbH, Kleve, Germany) using wavelengths $317.933 \mathrm{~nm}$ for Ca, $285.213 \mathrm{~nm}$ for $\mathrm{Mg}, 766.941$ $\mathrm{nm}$ for K, $177.495 \mathrm{~nm}$ for $\mathrm{P}$, and $589.592 \mathrm{~nm}$ for Na. Calibrations of instrument were performed using single element solutions (Inorganic Ventures, Christiansburg, VA) in the range from 0 to $25 \mathrm{mg} / \mathrm{L}$. The final amount of soluble minerals ( $\mathbf{M w}, \mathrm{g}$ ) was calculated as follows:

$$
\mathrm{Mw}=\left(\mathrm{D} \times \mathrm{Cd}_{1}^{2}\right) /\left(\mathrm{Cd}_{1}-\mathrm{Cd}_{2}\right),
$$

where $\mathrm{D}$ is the volume of supernatant collected for $\mathrm{d}_{1}(5$ $\mathrm{mL}), \mathrm{Cd}_{1}$ is the concentration of mineral in the fraction $\mathrm{d}_{1}$ determined by ICP-OES, and $\mathrm{Cd}_{2}$ is the concentration of mineral in the fraction $\mathrm{d}_{2}$ determined by ICPOES. Soluble mineral concentration in curd was determined as the ratio of $\mathrm{Mw}$ to the weight of curd (wt/ wt). Micellar concentration was calculated as difference between total and soluble mineral concentration.

Preliminary analysis showed that results for all traits were normally distributed. Outliers were defined as values deviating more than 3 standard deviations from the mean, and no outliers were detected according to this procedure. Pearson correlations ( $\mathrm{r}$ ) between mineral fractions content and chemical composition were assessed using the CORR procedure of SAS software ver. 9.4 (SAS Institute Inc., Cary, NC).

\section{Near-Infrared Spectroscopy Calibration Models}

Near-infrared spectra were obtained using 2 laboratory instruments and 1 portable device in the range of visible and NIR spectra as follows: (1) NIR regionFoodScan Lab, which operates in transmittance, collecting spectral variables every $2 \mathrm{~nm}$ for wavelengths between $850 \mathrm{~nm}$ and 1,050 nm (Lab-NIR); (2) visible and near-infrared region-NIRS DS2500 (Foss, Electric A/S), which operates in reflectance, recording spectral response every $0.5 \mathrm{~nm}$ between $400 \mathrm{~nm}$ and 2,500 nm (Lab-VIS-NIR); (3) NIR region-Scio Portable Device (VeriFood LTD, Herzliya, Israel), which operates in reflectance, recording spectral response on each wavelength between 740 and 1,070 nm (portable NIR); for the latter instrument, 5 scans were averaged to obtain the final spectrum.

Spectra were merged with reference values, and calibrations were developed using WinISI software (Infrasoft International, Port Matilda, PA) and modified partial least squares regression analysis combined with scatter correction $(\mathrm{NONE}=$ no correction; $\mathrm{DET}=$ detrending; $\mathrm{SNV}=$ standard normal variate; $\mathrm{SNV}+\mathrm{D}=$ standard normal variate + detrending; $\mathrm{MSC}=$ multiplicative scatter correction). Moreover, different math- 
ematical treatments were applied $(0,0,1,1 ; 1,10,10,1$; $1,4,4,1 ; 1,8,8,1 ; 2,5,5,1$; and $2,10,10,1$; where the first digit is the derivative, the second is the range of wavelength in which the derivative is calculated, the third is the number of wavelength used for the first smoothing, and the fourth is the number of wavelengths used for the second smoothing; Manuelian et al., 2017a). Nearinfrared spectra were excluded from prediction models when predicted data deviated more than 3 standard deviations from the mean of reference data. For each calibration model, the standard error in leave-one-out cross validation was calculated, and the mathematical treatment providing the best performance was selected. Fitting statistics were the standard error of calibration, the coefficient of determination in calibration, the coefficient of determination in leave-one-out cross validation, and the ratio of performance to deviation in leave-one-out cross validation (RPD).

\section{RESULTS}

\section{Curd Composition}

Total protein, soluble protein, humidity, fat, and ash of curd samples averaged 22.82, 2.08, 48.15, 27.16, and $3.44 \%$, respectively, and soluble protein and ash had the greatest coefficient of variation (Table 1). With regard to the curd mineral composition, the micellar fractions of $\mathrm{Ca}, \mathrm{Mg}$, and $\mathrm{P}$ were more abundant compared with their soluble fractions. Potassium was more present in the soluble phase, and $\mathrm{Na}$ was found only in the soluble phase. All minerals and their fractions had a coefficient of variation $\geq 0.15$; in particular, total $\mathrm{Na}$, soluble $\mathrm{P}$, micellar $\mathrm{K}$, and micellar $\mathrm{Mg}$ had coefficients of variation of $1.37,0.48,0.45$, and 0.36 , respectively (Table 1 ).

\section{Prediction Models}

Fitting statistics of calibration models for mineral fractions in curd are summarized in Table 2 for LabNIR, Table 3 for Lab-VIS-NIR, and Table 4 for portable NIR. Prediction models developed using spectra collected with Lab-NIR had RPD values between 1.25 (soluble $\mathrm{Mg}$ ) and 3.36 (total Na). Total $\mathrm{K}$ and its fractions had RPD lower than 2.00. The RPD values of total $\mathrm{Ca}$ and $\mathrm{Mg}$ were greater than their micellar and soluble fraction counterparts. Only micellar P could be predicted slightly better than total P (RPD of 2.88 and 2.70, respectively; Table 2). The Lab-VIS-NIR performed well for different minerals. Soluble P had RPD of 3.16, and micellar Ca and P showed RPD of 4.12 and 3.53 , respectively (Table 3 ). Considering total mineral content, $\mathrm{Na}$ and $\mathrm{Ca}$ had the best RPD (4.28 and 3.42, respectively). Total $\mathrm{K}$, its fractions, and soluble $\mathrm{Mg}$ were poorly predicted with RPD lower than 2.00. In general, for portable NIR, RPD values were lower than those obtained from the other 2 instruments (Table 4).

\section{Pearson Correlations}

Total protein was positively associated with micellar fractions, having correlation from 0.43 with micellar $\mathrm{K}$ to 0.82 with micellar $\mathrm{Ca}(P<0.001)$, and negatively associated with soluble Ca and $\mathrm{P}(\mathrm{r}=-0.71 ; P<0.001)$

Table 1. Mean, SD, CV, minimum, and maximum of predicted chemical composition and minerals content $(\mathrm{n}=83)$

\begin{tabular}{|c|c|c|c|c|c|}
\hline Trait & Mean & $\mathrm{SD}$ & $\mathrm{CV}$ & Minimum & Maximum \\
\hline \multicolumn{6}{|c|}{ Chemical composition (\%) } \\
\hline Total protein & 22.82 & 1.98 & 0.09 & 18.34 & 26.21 \\
\hline Soluble protein & 2.08 & 0.50 & 0.24 & 1.39 & 3.29 \\
\hline Humidity & 48.15 & 3.56 & 0.07 & 41.95 & 56.23 \\
\hline Fat & 27.16 & 1.92 & 0.07 & 22.68 & 32.08 \\
\hline Ash & 3.44 & 0.90 & 0.26 & 1.96 & 5.01 \\
\hline \multicolumn{6}{|c|}{ Mineral fraction $(\mathrm{mg} / \mathrm{g})$} \\
\hline Ca total & 6.95 & 1.43 & 0.21 & 3.83 & 11.15 \\
\hline Ca soluble & 1.38 & 0.38 & 0.27 & 0.73 & 2.00 \\
\hline Ca micellar & 5.57 & 1.72 & 0.31 & 2.43 & 10.42 \\
\hline $\mathrm{K}$ total & 0.88 & 0.13 & 0.15 & 0.46 & 1.17 \\
\hline K soluble & 0.61 & 0.10 & 0.16 & 0.36 & 0.87 \\
\hline $\mathrm{K}$ micellar & 0.27 & 0.12 & 0.45 & $<0.01$ & 0.63 \\
\hline Mg total & 0.28 & 0.05 & 0.20 & 0.16 & 0.42 \\
\hline $\mathrm{Mg}$ soluble & 0.12 & 0.02 & 0.15 & 0.08 & 0.17 \\
\hline $\mathrm{Mg}$ micellar & 0.16 & 0.06 & 0.36 & 0.05 & 0.32 \\
\hline Na total & 0.89 & 1.22 & 1.37 & 0.10 & 5.31 \\
\hline P total & 4.76 & 0.82 & 0.17 & 2.96 & 7.25 \\
\hline $\mathrm{P}$ soluble & 0.56 & 0.26 & 0.48 & 0.19 & 0.73 \\
\hline $\mathrm{P}$ micellar & 4.20 & 1.03 & 0.24 & 2.41 & 7.06 \\
\hline
\end{tabular}


Table 2. Calibration and cross validation statistics of prediction models for minerals content for near-infrared instrument (FoodScan Lab; Foss, Electric A/S, Hillerød, Denmark) ${ }^{1}$

\begin{tabular}{|c|c|c|c|c|c|c|c|}
\hline $\begin{array}{l}\text { Mineral } \\
\text { fraction } \\
(\mathrm{mg} / \mathrm{g})\end{array}$ & Model $^{2}$ & No. & SEC & $\mathrm{R}^{2}$ & SEcv & $\mathrm{R}^{2} \mathrm{cv}$ & $\mathrm{RPD}$ \\
\hline Ca total & SND1441 & 76 & 0.34 & 0.92 & 0.37 & 0.91 & 3.29 \\
\hline Ca soluble & SNV2551 & 80 & 0.16 & 0.83 & 0.19 & 0.75 & 2.02 \\
\hline Ca micellar & SND0011 & 78 & 0.37 & 0.95 & 0.50 & 0.90 & 3.16 \\
\hline K total & SND0011 & 75 & 0.07 & 0.65 & 0.10 & 0.39 & 1.29 \\
\hline K soluble & MSC2551 & 75 & 0.05 & 0.70 & 0.06 & 0.54 & 1.48 \\
\hline $\mathrm{K}$ micellar & SND0011 & 73 & 0.06 & 0.66 & 0.07 & 0.60 & 1.59 \\
\hline $\mathrm{Mg}$ total & MSC110101 & 76 & 0.01 & 0.91 & 0.02 & 0.90 & 3.22 \\
\hline Mg soluble & SNV2551 & 80 & 0.01 & 0.60 & 0.01 & 0.36 & 1.25 \\
\hline $\mathrm{Mg}$ micellar & MSC2551 & 77 & 0.01 & 0.91 & 0.02 & 0.87 & 2.78 \\
\hline Na total & SNV2551 & 79 & 0.25 & 0.95 & 0.33 & 0.91 & 3.36 \\
\hline P total & MSC210101 & 76 & 0.22 & 0.89 & 0.25 & 0.86 & 2.70 \\
\hline $\mathrm{P}$ soluble & SND2551 & 78 & 0.09 & 0.88 & 0.11 & 0.82 & 2.39 \\
\hline $\mathrm{P}$ micellar & SND210101 & 76 & 0.27 & 0.91 & 0.30 & 0.88 & 2.88 \\
\hline
\end{tabular}

${ }^{1} \mathrm{SEC}=$ standard error of calibration: $\mathrm{R}^{2}=$ coefficient of determination in calibration; SEcv = standard error in cross validation; $\mathrm{R}^{2} \mathrm{cv}=$ coefficient of determination in cross validation; $\mathrm{RPD}=$ ratio of prediction to deviation in cross validation.

${ }^{2}$ Scatter correction and statistical treatment used for spectra calibration; MSC (multiplicative scatter correction); SNV (standard normal variate); SND (standard normal variate + detrending). The first digit is the derivative, the second is the range of wave-length in which the derivative is calculated, the third is the number of wavelength used for the first smoothing, and the fourth is the number of wavelengths used for the second smoothing.

and soluble $\mathrm{K}(\mathrm{r}=-0.35 ; P<0.01)$ (Table 5). Overall, soluble protein was less associated with minerals compared with total protein; in particular, soluble protein was moderately correlated with soluble $\mathrm{P}(\mathrm{r}=-0.49$ : $P$ $<0.001)$ and total $\mathrm{Na}(\mathrm{r}=0.33 ; P<0.01)$, and weakly associated with other mineral fractions. Correlations of curd humidity with micellar fractions were moderately negative (from -0.67 to $-0.40 ; P<0.01$ ), whereas correlations with soluble $\mathrm{Ca}(P<0.001), \mathrm{K}(P<0.05)$, and $\mathrm{P}(P<0.001)$ were positive $(0.24$ to 0.52 ; Table 5$)$. Moderate to strong associations ( $\mathrm{r}=0.42$ to 0.86 , in absolute value; $P<0.01$ ) were estimated between ash

Table 3. Calibration and cross validation statistics of prediction models for minerals content for visible and near-infrared instrument (NIRS DS2500; Foss, Electric A/S, Hillerød, Denmark ) ${ }^{1}$

\begin{tabular}{|c|c|c|c|c|c|c|c|}
\hline $\begin{array}{l}\text { Mineral } \\
\text { fraction } \\
(\mathrm{mg} / \mathrm{g})\end{array}$ & Model $^{2}$ & No. & SEC & $\mathrm{R}^{2}$ & SEcv & $\mathrm{R}^{2} \mathrm{cv}$ & RPD \\
\hline Ca total & MSC1441 & 78 & 0.32 & 0.93 & 0.35 & 0.91 & 3.42 \\
\hline Ca soluble & SNV1441 & 78 & 0.09 & 0.94 & 0.16 & 0.81 & 2.32 \\
\hline Ca micellar & SND1441 & 77 & 0.32 & 0.95 & 0.36 & 0.94 & 4.12 \\
\hline K total & SNV110101 & 77 & 0.05 & 0.84 & 0.10 & 0.48 & 1.39 \\
\hline K soluble & SND2551 & 75 & 0.03 & 0.92 & 0.06 & 0.59 & 1.58 \\
\hline $\mathrm{K}$ micellar & NONE1441 & 73 & 0.05 & 0.70 & 0.07 & 0.41 & 1.31 \\
\hline $\mathrm{Mg}$ total & NONE1441 & 78 & 0.01 & 0.92 & 0.02 & 0.89 & 3.04 \\
\hline Mg soluble & SND1441 & 80 & 0.01 & 0.76 & 0.01 & 0.46 & 1.37 \\
\hline $\mathrm{Mg}$ micellar & NONE1441 & 77 & 0.01 & 0.91 & 0.02 & 0.88 & 2.94 \\
\hline Na total & MSC110101 & 79 & 0.16 & 0.98 & 0.26 & 0.94 & 4.28 \\
\hline P total & DET0011 & 77 & 0.21 & 0.90 & 0.23 & 0.87 & 2.81 \\
\hline $\mathrm{P}$ soluble & SND210101 & 78 & 0.03 & 0.99 & 0.08 & 0.90 & 3.16 \\
\hline $\mathrm{P}$ micellar & SNV210101 & 75 & 0.21 & 0.94 & 0.24 & 0.92 & 3.53 \\
\hline
\end{tabular}

${ }^{1} \mathrm{SEC}=$ standard error of calibration; $\mathrm{R}^{2}=$ coefficient of determination in calibration; $\mathrm{SEcv}=$ standard error in cross validation; $\mathrm{R}^{2} \mathrm{cv}=$ coefficient of determination in cross validation; $\mathrm{RPD}=$ ratio of prediction to deviation in cross validation.

${ }^{2}$ Scatter correction and statistical treatment used for spectra calibration; NONE (no scatter correction); DET (detrending); MSC (multiplicative scatter correction); SNV (standard normal variate); SND (standard normal variate + detrending). The first digit is the derivative, the second is the range of wave-length in which the derivative is calculated, the third is the number of wavelength used for the first smoothing, and the fourth is the number of wavelengths used for the second smoothing. 
Table 4. Calibration and cross validation statistics of prediction models for minerals content for near-infrared portable instrument (Scio Portable Device; VeriFood Ltd., Herzliya, Israel) ${ }^{1}$

\begin{tabular}{|c|c|c|c|c|c|c|c|}
\hline $\begin{array}{l}\text { Mineral } \\
\text { fraction } \\
(\mathrm{mg} / \mathrm{g})\end{array}$ & Model $^{2}$ & No. & SEC & $\mathrm{R}^{2}$ & SEcv & $\mathrm{R}^{2} \mathrm{cv}$ & $\mathrm{RPD}$ \\
\hline Ca total & DET1881 & 76 & 0.38 & 0.90 & 0.51 & 0.82 & 2.37 \\
\hline Ca soluble & NONE1441 & 82 & 0.17 & 0.80 & 0.22 & 0.67 & 1.74 \\
\hline Ca micellar & DET1881 & 76 & 0.39 & 0.93 & 0.55 & 0.86 & 2.73 \\
\hline K total & DET2551 & 74 & 0.09 & 0.36 & 0.11 & 0.13 & 1.08 \\
\hline K soluble & MSC210101 & 72 & 0.05 & 0.71 & 0.06 & 0.46 & 1.37 \\
\hline $\mathrm{K}$ micellar & NONE0011 & 74 & 0.08 & 0.55 & 0.09 & 0.47 & 1.39 \\
\hline $\mathrm{Mg}$ total & DET110101 & 78 & 0.02 & 0.88 & 0.02 & 0.80 & 2.25 \\
\hline Mg soluble & MSC1441 & 80 & 0.01 & 0.69 & 0.01 & 0.46 & 1.38 \\
\hline Mg micellar & DET0011 & 79 & 0.02 & 0.89 & 0.02 & 0.81 & 2.31 \\
\hline Na total & SND1881 & 76 & 0.39 & 0.88 & 0.49 & 0.80 & 2.26 \\
\hline $\mathrm{P}$ total & SNV2551 & 75 & 0.27 & 0.81 & 0.30 & 0.76 & 2.04 \\
\hline P soluble & NONE1441 & 80 & 0.08 & 0.91 & 0.11 & 0.82 & 2.40 \\
\hline $\mathrm{P}$ micellar & DET110101 & 76 & 0.37 & 0.83 & 0.41 & 0.79 & 2.19 \\
\hline
\end{tabular}

${ }^{1} \mathrm{SEC}=$ standard error of calibration; $\mathrm{R}^{2}=$ coefficient of determination in calibration; $\mathrm{SEcv}=$ standard error in cross validation; $\mathrm{R}^{2} \mathrm{cv}=$ coefficient of determination in cross validation; $\mathrm{RPD}=$ ratio of prediction to deviation in cross validation.

${ }^{2}$ Scatter correction and statistical treatment used for spectra calibration; NONE (no scatter correction); DET (detrending); MSC (multiplicative scatter correction); SNV (standard normal variate); SND (standard normal variate + detrending). The first digit is the derivative, the second is the range of wave-length in which the derivative is calculated, the third is the number of wavelength used for the first smoothing, and the fourth is the number of wavelengths used for the second smoothing.

and micellar and soluble mineral fractions (except for soluble Mg; $P>0.05$ ). Finally, the correlations between fat and mineral content, total $\mathrm{K}$ and curd composition, and soluble $\mathrm{Mg}$ and curd composition were weak and not statistically significant $(P>0.05$; Table 5$)$.

Within each mineral, the soluble phase was negatively correlated with total and micellar fraction (Table 6), except for the association between soluble and total $\mathrm{K}$ ( $\mathrm{r}=0.48 ; P<0.001)$, whereas the correlation between total and micellar fraction was positive, ranging from 0.72 for $\mathrm{K}$ to 0.99 for $\mathrm{Ca}(P<0.001)$. Total and micellar Ca were positively correlated with total $\mathrm{K}, \mathrm{Mg}, \mathrm{Na}$, and $\mathrm{P}$, exhibiting correlations from $0.24(P<0.05)$ to $0.98(P<0.001)$, and with micellar $\mathrm{K}, \mathrm{Mg}$, and $\mathrm{P}(\mathrm{r}=$ 0.57 to $0.99 ; P<0.001$ ), whereas associations of total and micellar $\mathrm{Ca}$ with soluble $\mathrm{K}$ and $\mathrm{P}$ were negative $(\mathrm{r}=-0.82$ to $-0.29 ; P<0.01$; Table 6$)$. Correlations between soluble $\mathrm{Ca}$ and other mineral fractions were of opposite sign compared with those of total and micellar Ca with other fractions. Similarly, total and micellar K correlated positively with total and micellar $\mathrm{Mg}$ and $\mathrm{P}$ $(\mathrm{r}=0.25$ to $0.74 ; P<0.05)$, and soluble $\mathrm{K}$ correlated negatively with total and micellar $\mathrm{Mg}$ and $\mathrm{P}(\mathrm{r}=-0.48$ to $-0.27 ; P<0.05)$. Moreover, soluble $\mathrm{K}$ correlated

Table 5. Pearson correlations between curd chemical composition and major mineral fractions

\begin{tabular}{|c|c|c|c|c|c|}
\hline $\begin{array}{l}\text { Mineral } \\
\text { fraction } \\
(\mathrm{mg} / \mathrm{g})\end{array}$ & $\begin{array}{c}\text { Total } \\
\text { protein } \\
(\%)\end{array}$ & $\begin{array}{c}\text { Soluble } \\
\text { protein } \\
(\%)\end{array}$ & $\begin{array}{c}\text { Humidity } \\
(\%)\end{array}$ & $\begin{array}{l}\text { Fat } \\
(\%)\end{array}$ & $\begin{array}{l}\text { Ash } \\
(\%)\end{array}$ \\
\hline Ca total & $0.79 * * *$ & $0.22^{*}$ & $-0.65^{* * *}$ & 0.02 & $0.85^{* * *}$ \\
\hline Ca soluble & $-0.71^{* * *}$ & $-0.22^{*}$ & $0.45^{* * *}$ & 0.11 & $-0.71^{* * *}$ \\
\hline Ca micellar & $0.82^{* * *}$ & $0.24^{*}$ & $-0.64^{* * *}$ & -0.01 & $0.86^{* * *}$ \\
\hline $\mathrm{K}$ total & 0.14 & -0.18 & -0.19 & 0.09 & 0.13 \\
\hline K soluble & $-0.35^{* *}$ & -0.04 & $0.24^{*}$ & -0.01 & $-0.42^{* *}$ \\
\hline $\mathrm{K}$ micellar & $0.43^{* * *}$ & -0.17 & $-0.40^{* *}$ & 0.11 & $0.48^{* * *}$ \\
\hline $\mathrm{Mg}$ total & $0.79^{* * *}$ & 0.15 & $-0.65^{* * *}$ & 0.04 & $0.82^{* * *}$ \\
\hline $\mathrm{Mg}$ soluble & -0.10 & 0.18 & 0.002 & 0.06 & -0.10 \\
\hline $\mathrm{Mg}$ micellar & $0.79^{* * *}$ & 0.09 & $-0.62^{* * *}$ & 0.02 & $0.82^{* * *}$ \\
\hline Na total & $0.38^{* *}$ & $0.33^{* *}$ & $-0.39^{* *}$ & 0.07 & $0.68^{* * *}$ \\
\hline P total & $0.78^{* * *}$ & 0.15 & $-0.67^{* * *}$ & 0.07 & $0.83^{* * *}$ \\
\hline P soluble & $-0.71^{* * *}$ & $-0.49^{* * *}$ & $0.52^{* * *}$ & 0.04 & $-0.74^{* * *}$ \\
\hline $\mathrm{P}$ micellar & $0.81^{* * *}$ & $0.24^{*}$ & $-0.67^{* * *}$ & 0.05 & $0.85^{* * *}$ \\
\hline
\end{tabular}




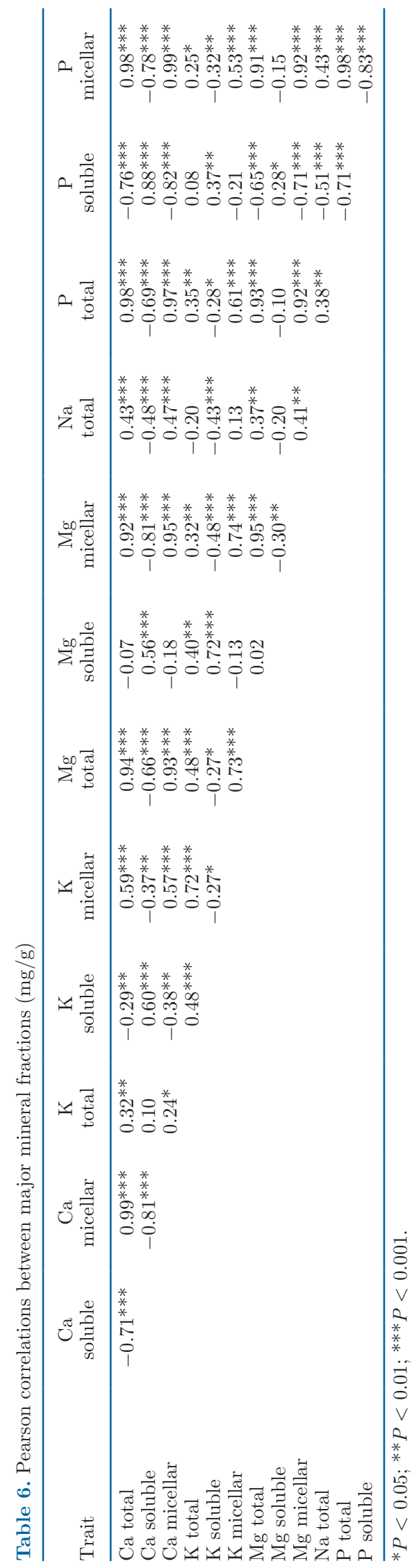

positively $(P<0.01)$ with soluble $\mathrm{Mg}(\mathrm{r}=0.72)$ and $\mathrm{P}(\mathrm{r}=0.37)$. Correlations between total $\mathrm{Mg}$ and other fractions mirrored those of micellar $\mathrm{Mg}$ with other fractions in terms of direction and magnitude (Table 6). Overall, moderate correlations were estimated between total $\mathrm{Na}$ and other mineral fractions ranging from $-0.51(P<0.001)$ to $0.47(P<0.001)$.

\section{DISCUSSION}

\section{Curd Composition}

The great variability of mineral content for the analyzed samples could be due to (1) the different geographical origin of samples, (2) different milk types and milk compositions and, (3) different manufacturing protocols across dairy companies. The chemical composition of curd samples was in accordance with results obtained in cheese and pasta filata by Manuelian et al. (2017b). To our knowledge, this is the first study that dealt with the determination of mineral content in curd samples; indeed, the scientific literature reports only a few studies on mineral composition determined in different types of cheese (Hassan et al., 2004; Fox et al., 2017). Calcium content in mozzarella cheese was $3.26 \mathrm{mg} / \mathrm{g}$ (Manuelian et al., 2017b) and $5.90 \mathrm{mg} / \mathrm{g}$ (Fox et al., 2017), and it was $6.34 \mathrm{mg} / \mathrm{g}$ (Hassan et al., 2004) and $8.33 \mathrm{mg} / \mathrm{g}$ (Lucey and Fox, 1993) in Cheddar cheese. Cichoscki et al. (2002) reported concentrations of major minerals in semihard Prato cheese maturated for a very short period $(1 \mathrm{~d})$ that were greater than those reported in the present study. Curd samples analyzed in our study were intended for mozzarella cheese production. We found greater content of minerals in curd compared with mozzarella cheese (Manuelian et al., 2017b), and this is likely attributable to the high temperature during manufacturing of pasta filata cheese that removes part of minerals through the whey.

Regarding the differentiation between soluble and micellar fractions of major minerals, only few studies have characterized such traits, and all dealt with Cheddar cheese (Lucey and Fox, 1993; Hassan et al., 2004). Previous studies reported a decrease of micellar Ca content, and consequently an increase of soluble fraction during ripening (Hassan et al., 2004; Lee and Lee, 2009). Hassan et al. (2004) reported total Ca content of $8.33 \mathrm{mg} / \mathrm{g}$ and micellar Ca content of $6.44 \mathrm{mg} / \mathrm{g}$ at $1 \mathrm{~d}$ of ripening, in agreement with results of the current study. Further trials are needed to establish the equivalence and bias between the proposed method and the previously published protocols, and to assess its precision and effectiveness as a gold standard method for the assessment of NIR instruments performances (Hassan et al., 2004). 


\section{Calibration Models}

Near-infrared spectroscopy calibration models for major mineral contents in milk (Costa et al., 2019; Visentin et al., 2019) and cheese have been discussed in the literature (Manuelian et al., 2017a), whereas no information on the prediction of soluble and micellar fractions in cheese or curd is currently available. As proposed by Williams (2014), the accuracy of calibration models can be evaluated through RPD statistics. In particular, RPD values smaller than 2.0 are not recommended for industry application; values between 2.0 and 3.0 limit the opportunity of using prediction models only for screening purposes; values between 3.1 and 3.4 underline good prediction ability of the models and the opportunity of using them for quality control; values between 3.5 and 4.0 highlight good prediction models and the opportunity of using them for on-line control in food process operations; values greater than 4.00 are considered suitable for any application. Both in terms of RPD and $\mathrm{R}^{2}$, the Lab-VIS-NIR instrument showed the best performances. This is likely due to the broader wavelength spectrum and to the higher resolution of Lab-VIS-NIR (400-2,500 $\mathrm{nm}$ and $0.5 \mathrm{~nm}$, respectively) compared with the wavelength spectra and resolutions of Lab-NIR (850-1,050 $\mathrm{nm}$ and $2 \mathrm{~nm}$, respectively) and portable NIR (740-1,070 $\mathrm{nm}$ and $1 \mathrm{~nm}$, respectively). Regarding NIR transmittance technology, prediction models showed RPD of 3.29, 1.29, 3.22, 3.36 and 2.70 for $\mathrm{Ca}, \mathrm{K}, \mathrm{Mg}, \mathrm{Na}$, and $\mathrm{P}$, respectively, which are lower than those reported by Manuelian et al. (2017a), except for Na. Possible reasons to explain differences between our results and those of Manuelian et al. (2017a) are the sample size and the variability of data. Manuelian et al. (2017a) used 145 cheese samples (different types, from fresh to hard cheeses), which resulted in high standard deviations compared with our study. The RPD values of prediction models developed using spectra collected by Lab-VIS-NIR (which works in reflectance mode) ranged from 1.39 (total $\mathrm{K}$ ) to 4.28 (total Na). Lucas et al. (2008) investigated the feasibility of predicting mineral content in cheese using NIR reflectance spectroscopy in a data set of 445 samples and reported greater RPD for $\mathrm{Ca}$ (4.56) and $\mathrm{K}$ (2.14), and lower RPD for $\mathrm{Mg}$ (2.33) compared with the present study. Regarding portable NIR, previous studies investigated only prediction of fat and moisture content of cheese, testing different mathematical treatments. We focused on major minerals obtaining RPD between 1.08 and 2.73 , meaning that some calibration may be used for screening purposes. It is worth noting that portable NIR can predict micellar minerals with better accuracy compared with total minerals (Wiedemair et al., 2019).

\section{Correlations}

Considering that the matrix of the present study was curd, significant associations of total protein with micellar and total minerals were expected. Indeed, most of milk mineral is contained in the casein reticulum formed after milk coagulation; only a small fraction is lost in the soluble phase, especially during cheese manufacturing (Fox et al., 2017). This was also confirmed by the association between total proteins and micellar minerals (Table 5). In regards to humidity, a significant positive correlation with soluble mineral fractions was expected because part of the minerals was lost with the whey after reaching mineral equilibrium in the curd matrix. It is worthy to report that the loss of micellar minerals depends also on the $\mathrm{pH}$ values of the curd under whey during the cheesemaking process. The timing of this manufacturing step may have influenced the mineral composition at a single curd level, and may explain (at least partially) the variability of mineral composition across curds involved in the present study. Instead, total mineral fraction showed negative correlation with humidity because curd minerals were mostly composed by micellar minerals that were trapped in the curd matrix (Fox et al., 2017). The associations between ash, protein, and mineral contents were similar or higher than those reported by Cichoscki et al. (2002) for 108 cheese samples. In fact, those authors reported a correlation of $0.75(P<0.001)$ between ash and $\mathrm{Na}$, and $0.51,0.80$, and $0.39(P<0.001)$ between protein content and $\mathrm{Ca}, \mathrm{P}$, and $\mathrm{Mg}$, respectively. In particular, curd ash content tended to increase when the soluble phase of minerals decreased (Fox et al., 2017). The strong correlation between total and micellar phases in all minerals was expected, considering that curd can be imagined as a concentration of milk solids, and micellar fractions of $\mathrm{Ca}, \mathrm{P}$, and $\mathrm{Mg}$ are almost totally found in casein micelles. All correlations between total $\mathrm{Na}$ and total phase of other minerals were stronger and positive compared with those reported by Cichoscki et al. (2002), who observed correlations of -0.34 and $-0.35(P<0.01)$ between $\mathrm{Na}$ and $\mathrm{Mg}$, and $\mathrm{Na}$ and $\mathrm{Ca}$, respectively. The very strong relationship between micellar $\mathrm{Ca}$ and $\mathrm{P}(\mathrm{r}=0.99)$ was expected, considering the strict chemical relationship they have as constituents of the micellar calcium phosphate, which is an essential component of the casein micelle (Holt, 2016). The strong correlation between micellar phases of $\mathrm{Mg}$, $\mathrm{Ca}$, and $\mathrm{P}$ resembled those estimated by Lucas et al. (2008) for 445 samples of cheese. Moreover, a similar association between total $\mathrm{Ca}$ and total $\mathrm{Mg}(0.71 ; P$ $<0.001)$ was assessed by Cichoscki et al. (2002): Mg can be thought of as a competitor of $\mathrm{Ca}$ during the 
curd formation process because both $\mathrm{Ca}$ and $\mathrm{Mg}$ act as a bond between casein micelles (Alexander and Ford, 1957; Malacarne et al., 2014).

\section{Implications}

Calibrations described in the current study can be used for different purposes, from screening to process or quality control, with applications in field conditions. The portable device is cheaper, faster, and easier to be handled by operators compared with laboratory instruments, but it is useful only for screening purposes, whereas laboratory instruments are potentially useful to control any process that involves curd. According to the correlations estimated in the present study, the Italian dairy industry may be able to make decisions regarding curd management and handling from the knowledge of the concentration of a group of minerals or their micellar phase. In addition, the possibility to predict soluble and micellar mineral fractions could provide the industry a valuable instrument to rapidly evaluate the quality of curd according to an on-site or on-line approach.

\section{CONCLUSIONS}

The determination of mineral fractions is important to evaluate the quality of commercial frozen and fresh curds and for prompt decision-making at the industry level. The present study dealt with the characterization of total, micellar, and soluble contents of 5 major minerals ( $\mathrm{Ca}, \mathrm{Mg}, \mathrm{K}, \mathrm{P}, \mathrm{Na}$ ) predicted in curd intended for mozzarella manufacture. The accuracy of prediction of different NIR instruments was also discussed. Overall, micellar and total phase of the same mineral were strongly correlated; instead, the soluble phase was negatively associated with both micellar and total fractions, especially for Ca and P. Considering calibration models in terms of RPD, the laboratory instrument operating in visible and NIR regions had higher performances for all mineral fractions, except for micellar $\mathrm{K}$, total Mg, and soluble Mg. In general, the portable NIR device showed lower precision compared with the laboratory instruments, and its application is likely limited to screening purposes.

\section{ACKNOWLEDGMENTS}

We gratefully acknowledge the "Innovazioni di processo e di prodotto nel settore caseario per un miglioramento della qualità, delle proprietà salutistiche, della shelf-life e della sostenibilità ambientale - LatTraZione 2020 - CDS000628" project funded by Sabelli (Ascoli
Piceno, Italy). The authors have not stated any conflicts of interest.

\section{REFERENCES}

Alexander, T. G., and T. F. Ford. 1957. Magnesium in the caseincontaining colloid of milk. J. Dairy Sci. 40:1273-1276. https://doi .org/10.3168/jds.S0022-0302(57)94625-8.

Cichoscki, A. J., E. Valduga, A. T. Valduga, M. E. Tornadijo, and J. M. Fresno. 2002. Characterization of Prato cheese, a Brazilian semi-hard cow variety: Evolution of physico-chemical parameters and mineral composition during ripening. Food Control 13:329336. https://doi.org/10.1016/S0956-7135(02)00039-7.

Costa, A., G. Visentin, M. De Marchi, M. Cassandro, and M. Penasa. 2019. Genetic relationships of lactose and freezing point with minerals and coagulation traits predicted from milk mid-infrared spectra in Holstein cows. J. Dairy Sci. 102:7217-7225. https://doi .org/10.3168/jds.2018-15378.

De Marchi, M., V. Toffanin, M. Cassandro, and M. Penasa. 2014. Invited review: Mid-infrared spectroscopy as phenotyping tool for milk traits. J. Dairy Sci. 97:1171-1186. https://doi.org/10.3168/ jds.2013-6799.

Fox, P. F., T. P. Guinee, T. M. Cogan, and P. L. H. McSweeney. 2017. Salting of cheese curd. Pages 251-277 in Fundamentals of Cheese Science. Springer, Boston, MA.

Franzoi, M., G. Niero, M. Penasa, M. Cassandro, and M. De Marchi. 2018. Technical note: Development and validation of a new method for the quantification of soluble and micellar calcium, magnesium, and potassium in milk. J. Dairy Sci. 101:1883-1888. https:/ /doi.org/10.3168/jds.2017-13419.

Hassan, A., M. E. Johnson, and J. A. Lucey. 2004. Changes in the proportions of soluble and insoluble calcium during the ripening of Cheddar cheese. J. Dairy Sci. 87:854-862. https://doi.org/10 .3168/jds.S0022-0302(04)73229-4.

Holt, C. 2016. Casein and casein micelle structures, functions and diversity in 20 species. Int. Dairy J. 60:2-13. https://doi.org/10 .1016/j.idairyj.2016.01.004.

Lante, A., G. Lomolino, M. Cagnin, and P. Spettoli. 2006. Content and characterisation of minerals in milk and in Crescenza and Squacquerone Italian fresh cheeses by ICP-OES. Food Control 17:229-233. https://doi.org/10.1016/j.foodcont.2004.10.010.

Lee, M. R., and W. J. Lee. 2009. The role of Ca equilibrium on the functional properties of cheese: A review. Korean J. Food Sci. Anim. Resour. 29:545-549. https://doi.org/10.5851/kosfa.2009.29 .5 .545 .

Lucas, A., D. Andueza, E. Rock, and B. Martin. 2008. Prediction of dry matter, fat, $\mathrm{pH}$, vitamins, minerals, carotenoids, total antioxidant capacity, and colour in fresh and freeze-dried cheeses by visible-near-infrared reflectance spectroscopy. J. Agric. Food Chem. 56:6801-6808. https://doi.org/10.1021/jf800615a.

Lucey, J. A., and P. F. Fox. 1993. Importance of calcium and phosphate in cheese manufacture: A review. J. Dairy Sci. 76:1714-1724. https://doi.org/10.3168/jds.S0022-0302(93)77504-9.

Malacarne, M., P. Franceschi, P. Formaggioni, S. Sandri, P. Mariani, and A. Summer. 2014. Influence of micellar calcium and phosphorus on rennet coagulation properties of cows milk. J. Dairy Res. 81:129-136. https://doi.org/10.1017/S0022029913000630.

Manuelian, C. L., S. Currò, M. Penasa, M. Cassandro, and M. De Marchi. 2017b. Characterization of major and trace minerals, fatty acid composition, and cholesterol content of Protected Designation of Origin cheeses. J. Dairy Sci. 100:3384-3395. https://doi.org/10 .3168/jds.2016-12059.

Manuelian, C. L., S. Currò, G. Visentin, M. Penasa, M. Cassandro, C. Dellea, M. Bernardi, and M. De Marchi. 2017a. Technical note: At-line prediction of mineral composition of fresh cheeses using near-infrared technologies. J. Dairy Sci. 100:6084-6089. https:// doi.org/10.3168/jds.2017-12634.

Reykdal, O., S. Rabieh, L. Steingrimsdottir, and H. Gunnlaugsdottir. 2011. Minerals and trace elements in Icelandic dairy products 
and meat. J. Food Compos. Anal. 24:980-986. https://doi.org/10 .1016/j.jfca.2011.03.002.

Visentin, G., G. Niero, D. P. Berry, A. Costa, M. Cassandro, M. De Marchi, and M. Penasa. 2019. Genetic (co)variances between milk mineral concentration and chemical composition in lactating Holstein-Friesian dairy cows. Animal 13:477-486. https://doi.org/10 $.1017 /$ S1751731118001507.

Visentin, G., M. Penasa, P. Gottardo, M. Cassandro, and M. De Marchi. 2016. Predictive ability of mid-infrared spectroscopy for major mineral composition and coagulation traits of bovine milk by using the uninformative variable selection algorithm. J. Dairy Sci. 99:8137-8145. https://doi.org/10.3168/jds.2016-11053.

Wiedemair, V., D. Langore, R. Garsleitner, K. Dillinger, and C. Huck. 2019. Investigations into the Performance of a novel pocket-sized near-infrared spectrometer for cheese analysis. Molecules 24:428. https://doi.org/10.3390/molecules24030428.

Williams, P. 2014. The RPD statistic: A tutorial note. NIR News 25:22-26. https://doi.org/10.1255/nirn.1419.

\section{ORCIDS}

M. Saugo () https://orcid.org/0000-0002-9979-2153

M. Franzoi ๑ https://orcid.org/0000-0001-8701-5632

G. Niero $\odot$ https://orcid.org/0000-0002-6169-1162

M. De Marchi $\odot$ https://orcid.org/0000-0001-7814-2525 